\title{
Safety Management in a Manufacturing Company: Six Sigma Approach
}

\author{
Lateef Ur Rehman Ateekh-ur-Rehman \\ Department of Industrial Engineering, King Saud University, Riyadh, KSA \\ Email: arehman@ksu.edu.sa
}

Received April 24, 2012; revised May 20, 2012; accepted June 1, 2012

\begin{abstract}
The manufacturing company under consideration recorded the high accident rates for last few years. These accidents cause the organization the heavy man-day loss, the production loss and heavy costs of insurance. The objective of health and safety department at the manufacturing company was to set and improve accidents prevention system. The paper presents how does the six-sigma technique will help to evaluate the safety and environmental hazards in performance of organizations? It is observed that the study helped the management to measure, analyze and improve overall safety plan to protect the life and health of the employees.
\end{abstract}

Keywords: Manufacturing; Safety; Six-Sigma

\section{Introduction}

In 1987, Motorola introduced the Six-Sigma technique. Their objective was to reduce process output variation so that six standard deviation lie between the mean and the nearest specification limit. According to this technique in a lot of one million opportunities, 3.4 defects (per million) are allowed. In other words this is also known as defects per million opportunities (DPMO) [1]. It is evident from various mode of publish media that currently most of the industries manufactures $2 \%$ to $3 \%$ errors in a lot of one million industrial operations [2]. Large companies, for example Motorola, Samsung, Sony and Honeywell are using six-sigma as an improvement tool. This is due to the emphasis on design and manufacturing to international standard by acquiring some of the best technologies/improvement techniques from leading companies in the world, together with technologies developed in its own facilities. The survey of hundred manufacturing companies by Thomas et al. [3] highlights that the effective implementation of six sigma leads to greater opportunities for companies to achieve economic sustainability through continuous growth and manufacturing efficiency. On the other hand, Peter et al. [4] reports there is need of employee-management consensus approach to continuous improvement in safety management in the workplace is essential.

It is evident that the international labor organization (ILO) and world health organization (WHO) are concerned with protecting the safety, health and welfare of people engaged in work in any industrial or non indus- trial organization. One of the principal objectives of any manufacturing organization is that of developing and promoting the right safety culture. They wish to do improvements in the area of safety, health, and environmental protection. This paper reports a study to enhance the level of safety among the workers at one of the manufacturing organization in Kingdom of Saudi Arabia. Sixsigma technique is used herewith, to define opportunities, measure performance, analyze opportunity, improve, and control performance.

The paper is organized in numerous sections. To start with initially background of the manufacturing company is presented, followed by a brief review about the relevance of six-sigma in industrial safety. Subsequently the detail application of DAMIC (Define, Measure, Analyze, Improve and Control) model is presented. At the end the paper concludes with the future scope of the present study.

\section{Background of the Company}

The company is founded in the year 1955 in Saudi Arabia. It's one of the largest enterprises in the sector of engineering and manufacturing. The company is active in Structural Steel, Steel Pipes and Galvanizing Services. Today, it is one of the most successful and reputed suppliers of products to local and international markets. This enviable reputation has been achieved by focusing on the individual needs of customer in each product \& services, and then applying expertise and resources to develop and supply products, that provide value. This is also due to 
the emphasis on design and manufacturing to international standard by acquiring some of the best technologies/improvement techniques from leading companies in the world, together with technologies developed in its own facilities. One of the principal objectives of the company is that of developing and promoting the right safety culture. A substantial number of workplace accidents are instigated through unsafe behavior. The financial loss associated with accidents necessitates the adoption of process improvements in the area of safety, health, and environmental protection. The company on hand is presently implementing Quality Health Safety Environment management system (QHSE system) under the leadership of HSE (Health Safety Environment) department. The objective of HSE dept is to monitor, analyze and evaluate different work hazards (physical, chemical, electrical, civil and or mechanical so on) at workplace. Subsequently work on modifying safety rules and procedures to fit the international standards. HSE dept observed that six-sigma has received considerable attention as an improvement approach by Quality department in their company. As its popularity has grown, inevitably the question has arisen, how can this method be applied to industrial safety? A brief review of literature in this regard is presented in the following section.

\section{Literature Review: Six Sigma and Safety}

Safety has a significant role in industrial organizations. It is evident from the past literature [5-9] that employee awareness of safety plays an important role in quality outcome. Poor awareness of safety indicates a poor safety climate and is linked to decreases in the actual health and safety of employees. The duty of any operations manager is how he/she can improve worker performance in general and quality outcomes in particular. The purpose of the present study is to integrate industrial safety and six sigma approach. A brief literature review of selected articles is presented hereunder.

Stricoff and Seymour [10] described six-sigma and one way it can be applied in the safety arena. Joseph Staryarsky and Whitfield [11] presented the building blocks necessary to help manufacturing organization to move towards "World Class" Safety performance, which resulted in a major reduction in lost workdays due to on-the-job accidents. Bahadir and Ivan [12] discuss utilization of Six Sigma management strategies in ship maintenance and safety, in addition to its applicability and benefits. Peter et al. [4] presented the six sigma process framework in performance management to explore and improve the injury rate of an international waste disposal firm as a case study. Ng et al. [13] presented the application of six-sigma approach to reduce fall hazards among cargo handlers working on top of cargo containers.

\section{Improve Safety: Six Sigma Approach}

The objective of this study is to use six-sigma technique to identify and reduce the occurrences of accidents at the company in consideration. The tools of six-sigma techniques were applied are as Define, Measure, Analyze, Improve and Control (DAMIC). In define phase, the safety level and rate of accidents was identified through past statistics and survey. Main and sub causes for the variation in safety level are measured through questionnaire survey (Note: the questionnaire will be made available to readers on request). In analyze phase, those causes were verified and subsequently, critical causes were identified. And finally, in improve phase and control phase recommendations were developed to improve the safety level.

\subsection{Define and Measure Phase of Six-Sigma}

This section presents the first two steps of six-sigma techniques as: define and measure phase.

\subsubsection{Define Phase}

It is observed that for the manufacturing company in the study has a high accidents rate. The accidents that took place in the manufacturing company for the period of January to December 2010 are presented in Figure 1. The Figure 2 shows the department wise split of number of accidents. This is causing too many man-day loss, high insurance cost and property damage cost. It appears that the company is already buying a lot of money to keep their facility safe, but there policy seems to fail at some point. The concern of management of the company is to reduce these losses in future and improve the safety policy. The safety operating expenses incurred by the management are presented in Table 1. Similarly, due to accidents there is damage to company's property, which is accounted as property damage cost. The Table 2 presents that in the past year the factory indorses a loss in both equipments and money due to number of accidents that took place in the finishing department alone. The numbers of damaged equipments and their related costs are huge and are to be a concern in near future if the company wants to maintain or expand business.

It is observed that the worker's accidents varies from superficial wounds to sever injures and even fatality.

The past record shows that there is not only high number of accident per month, but the accidents are dangerous to the lives of employees and or workers. For example last year first time in the history of the company a young technician died in finishing department on duty. So, form the information presented in previous paragraphs, it was obvious that the department that needs focus of attention is the manufacturing and finishing departments. Due to the direct instructions from the management of the company and may be due to the huge loss 


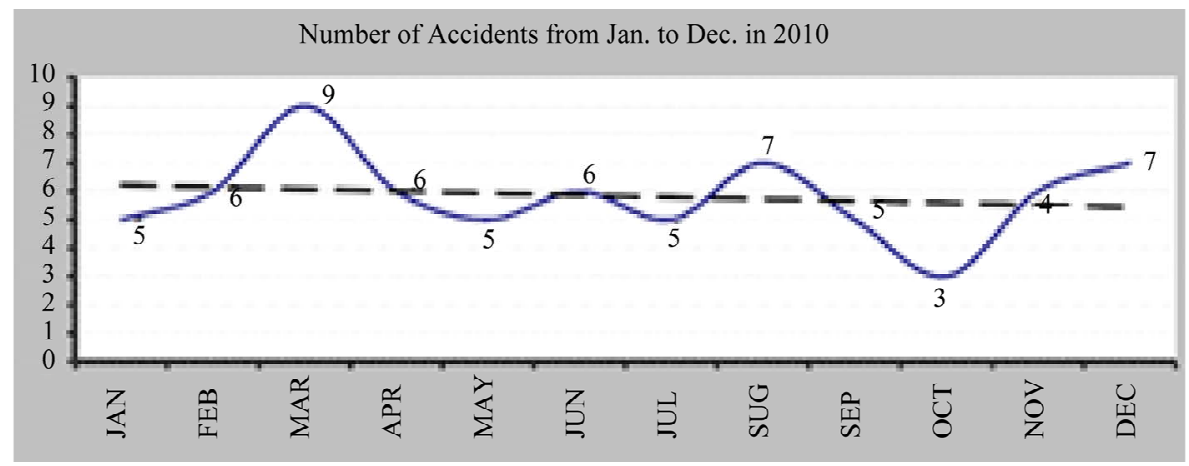

Figure 1. Number of accidents from Jan to Dec 2010.

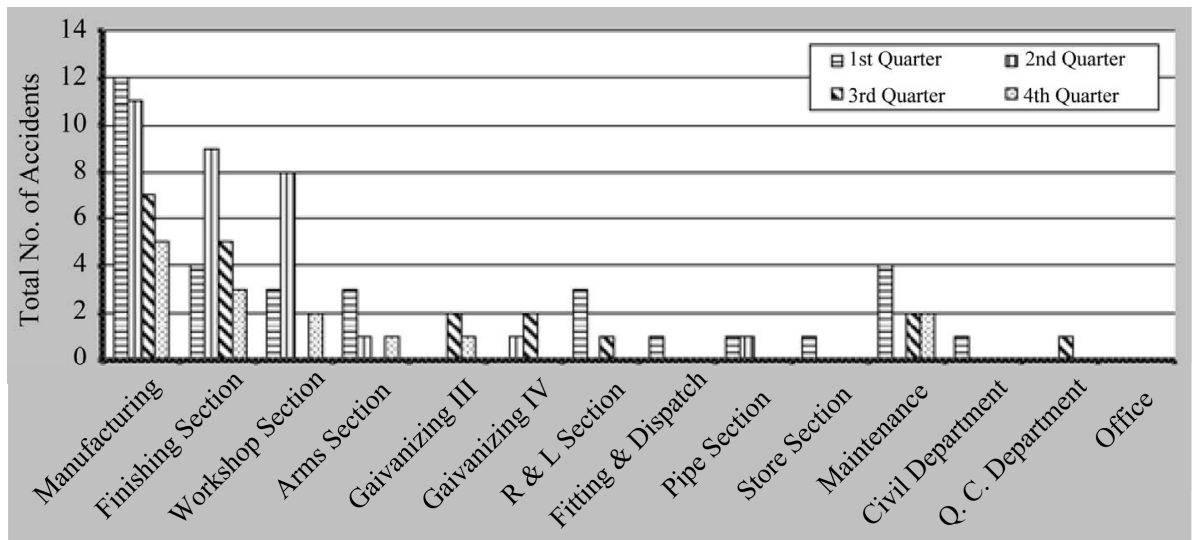

Figure 2. Number of accidents department wise.

Table 1. Safety plan and related cost.

\begin{tabular}{ccc}
\hline Safety plan & Duration & Cost \\
\hline Maintenance of fire extinguisher & Every 6 months & 10 SR per month per fire extinguisher \\
Refill the empty fire extinguisher cylinder & When empty cylinders available \\
$\begin{array}{c}\text { Maintenance of the fire alarm/fighting system } \\
\text { Inspection of the forklifts, cranes, boiler, pressure tanks } \\
\text { and underground diesel tank }\end{array}$ & Twice in a year \\
Measurement of Air Quality and Analyze wastewater & Once in a year & 28,000 SR per year \\
\hline
\end{tabular}

Table 2. Property damaged cost for the year 2010.

\begin{tabular}{ccc}
\hline Property damaged & Quantity & Total cost \\
\hline Forklift's fork & 3 & $4220 \mathrm{SR}$ \\
Luminary & 9 & $1980 \mathrm{SR}$ \\
Sling & 14 & $910 \mathrm{SR}$ \\
Machine control panel & 19 & $6710 \mathrm{SR}$ \\
Machine frame & 8 & $4070 \mathrm{SR}$ \\
Machine Guard & 23 & $8852 \mathrm{SR}$ \\
Floor damaged & 2 & $1190 \mathrm{SR}$ \\
Exhaust Fans & 0 & $0 \mathrm{SR}$ \\
Electric cable & 1 & $450 \mathrm{SR}$ \\
Welding Machine & 1 & $935 \mathrm{SR}$ \\
Materials damaged & 34 & $10,080 \mathrm{SR}$ \\
Total & 114 & $39,397 \mathrm{SR}$ \\
\hline
\end{tabular}


of a human life in the finishing department, the focus of study was limited to finishing department. Subsequently next objective was set to measure the relevant data in support of the decision making and action to be taken to uncover the real issues/factors related to low safety hazard level in the finishing department.

\subsubsection{Measure Phase}

About one hundred and fifty total workers (in finishing department) were interviewed using the initial survey questionnaire to list out the factors/main causes that are associated with their work safety. The outcome highlights that: worker background, workplace environment, bad jobs/tools/equipments handling, poor housekeeping, carelessness and lack of awareness of personal protective equipments (PPE) are the main causes. Thus this information provided the basis for a larger scale questionnaire to identify the critical main and sub causes or factors related to accident vulnerability in finishing department. Based on the information collected from the experienced workers, a safety measurement tree was constructed according to six-sigma technique.

Similarly, since the workers were supervised, instructed, \& hired by the administrative personal, it needed to make sure to sort the safety issues by verifying \& questioning the managers \& supervisors. The tree is then updated (refer Figure 3) with the information collected form managers, heads of department \& supervisors.

To further substantiate, the major questionnaire survey was conducted. The questionnaire was developed based upon the above define phase, and one to one detail discussion with safety engineers and the management of the company. There was three different set of questionnaire; the first was for worker, the second for the supervisors and the third for the managers (refer Appendix). Initially a pilot survey was conducted. Subsequently revised sets of questionnaire were used in large scale survey. One hundred and twenty respondents participated in the final survey. The test-retest method was used [14]. Thus the respondents were requested to complete the same set of questionnaire twice within a few hours gap in between. The order of questions were also rearranged to be different between first set and second set to avoid copying using memory. The survey results and its analysis is as presented in the following analyze phase.

\subsection{Analyze Phase}

This section presents how survey results are used to do the analysis of viewpoints of workers, managers and supervisors. This section also presents our views on the current facilities and layout and the type of injuries.

Based on the outcome of questionnaire based survey, it is clear from Figure $\mathbf{4}$ that the main cause/factor related to low safety level of worker, seems to be worker background/culture. This indicates that there is something wrong in the workers behavior, which has been investigated by dividing the main cause into sub causes. Similarly, the workplace environment is next subsequent cause. It is worthy to investigate this cause as well. It is also evident that there is satisfaction of worker towards the safety system in the department and safety equipments that are made available to them. Subsequently the questionnaire based survey results are used to evaluate the background of worker in the finishing department. The details are as presented in Figure 6. It is evident from Figure 5 that worker culture (the country culture he belongs) is the sub-cause for low safety level, followed by his skill and experience.

Number of observations is made through the output of survey questionnaire analysis and one to one in-depth interaction with the managers, supervisors and workers. Few of the observations are made and presented here. There is wide gap in communication and interface between managers and workers. It is very-very low rated.

The workers complain that the managers and supervisors do not effectively solve the reported issues related to

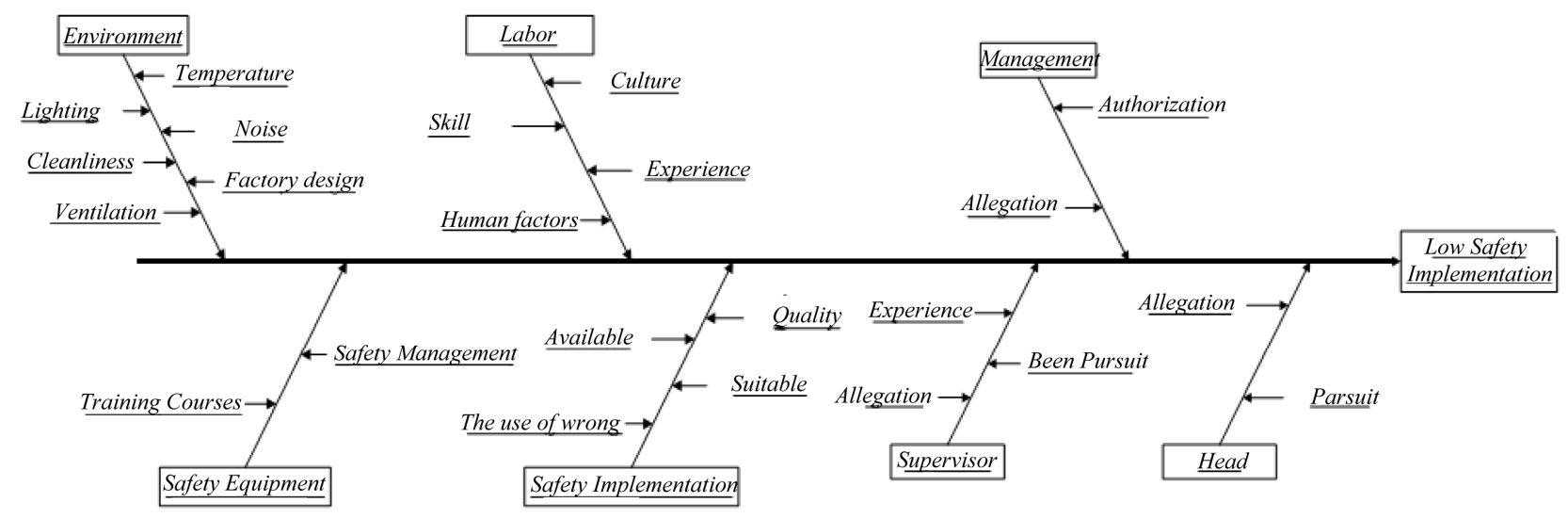

Figure 3. A causes and effect diagram to measure safety. 
Main Causes Average Weight

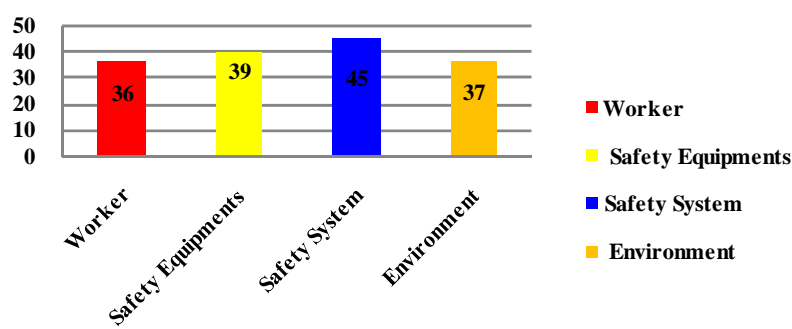

Figure 4. Outcome of survey responses from workers.

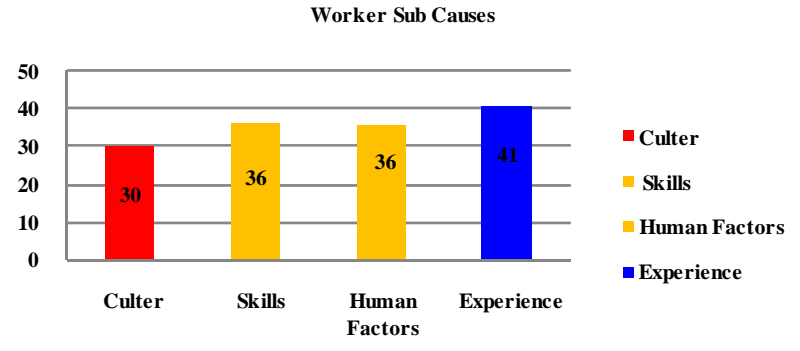

Figure 5. Outcome of survey responses related to worker background.

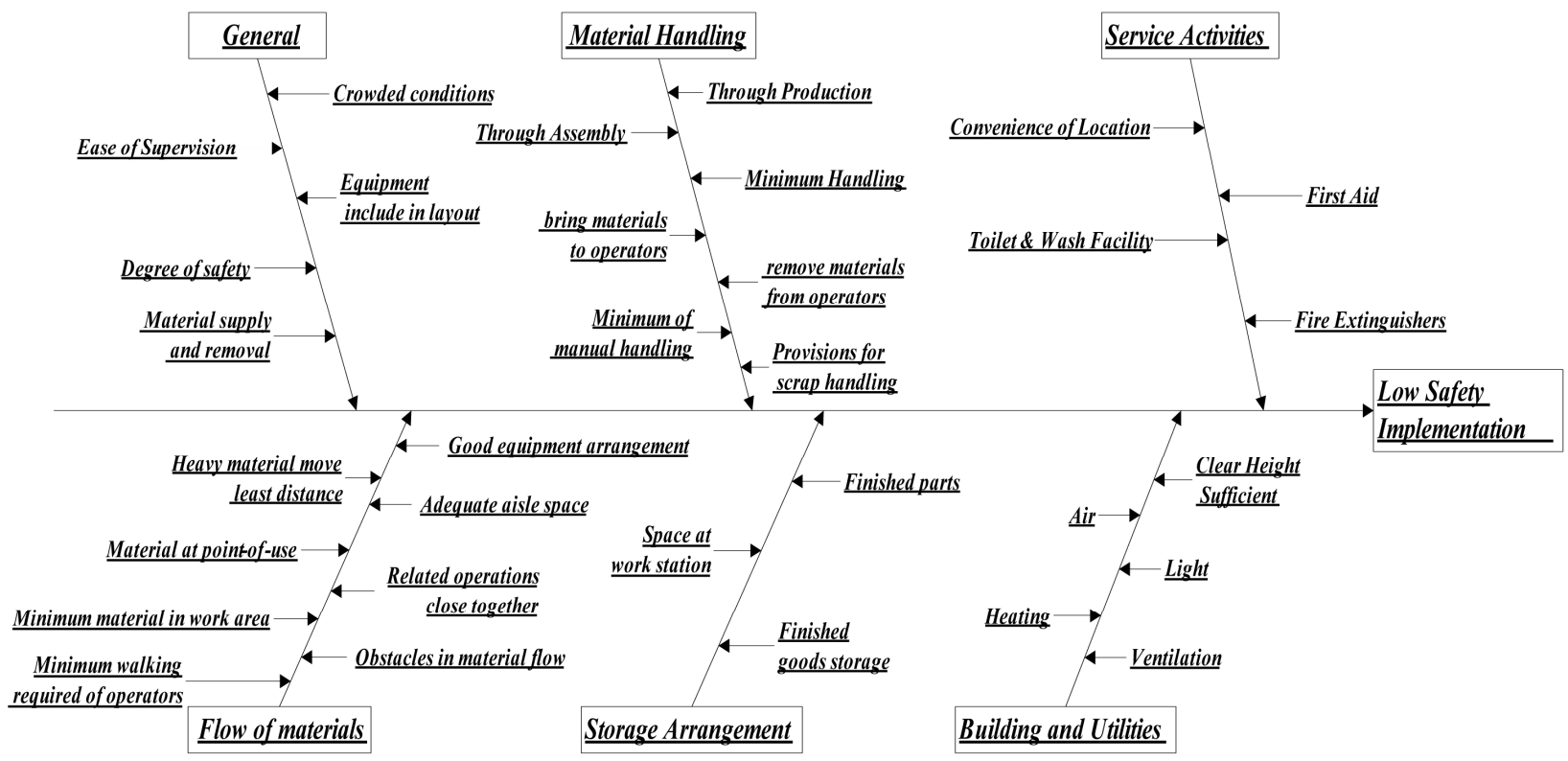

Figure 6. Cause and effect diagram related to safety implantation problems with respect to plant layout and facilities.

safety problems.

On the other hand the supervisor complains that the workers always violate safety instructions, and they (workers) do not welcome consolations regarding safety maters. Safety courses usually are not included in the main induction training course. 50\% of the workers don't make out the basic safety rules. There is no authority given to safety department or any personal to neither inform nor punish undisciplined worker. There is no reward system to anyone who is committed to PPE or other safety regulations.

Supervisors responded that the worker's annual evaluation doesn't include a safety section. The workers have obligation of wearing PPE in summer $60 \%$ and in winter $80 \%-85 \%$. But most of the respondent reported that the helmet and the ear plugs provided to employees are not suitable at all.

The facilities provided and the layout of workplace area is one of the factors that change the behavior of manpower working in the department. The plant layout evaluation was analyzed, revised and modified to suit the existing situation in finishing department. Figure 6 shows the cause and effect diagram related to safety implantation problems with respect to plant layout and facilities. From the responses to the questionnaire related to plant layout and facilities, it is observed that there is good rating to flow of material, material handling, and storage arrangement in the finishing department. On the other hand very low rating to utilities and services provided to production workers (refer Figure 7). It's clear from observation and workers responses to the questionnaire that ventilation and high temperature are major problems and which have a bad influence on the health and their (workers) performance.

In analyzing any production related problem one always investigate the defected part. Since in the study objective is to reduce the level of safety hazards, in such case one should investigate the injured person, his/her injured body part, and the type of injures. The fishbone in Figure 8 presents the reasons behind the type of injury. After further investigation, Figure 9 highlights that the hand injures have the highest rate in finishing department. 

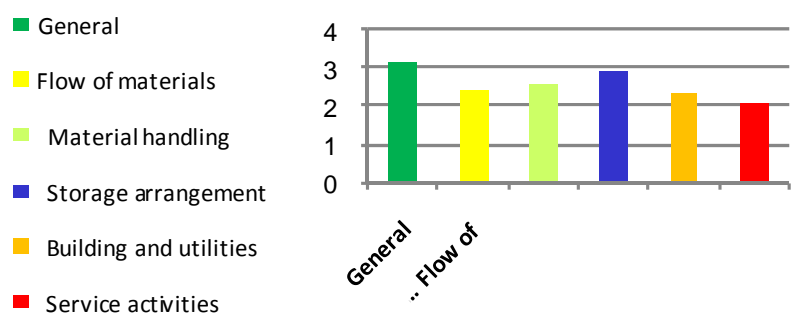

Figure 7. Evaluation of plant layout and facilities.

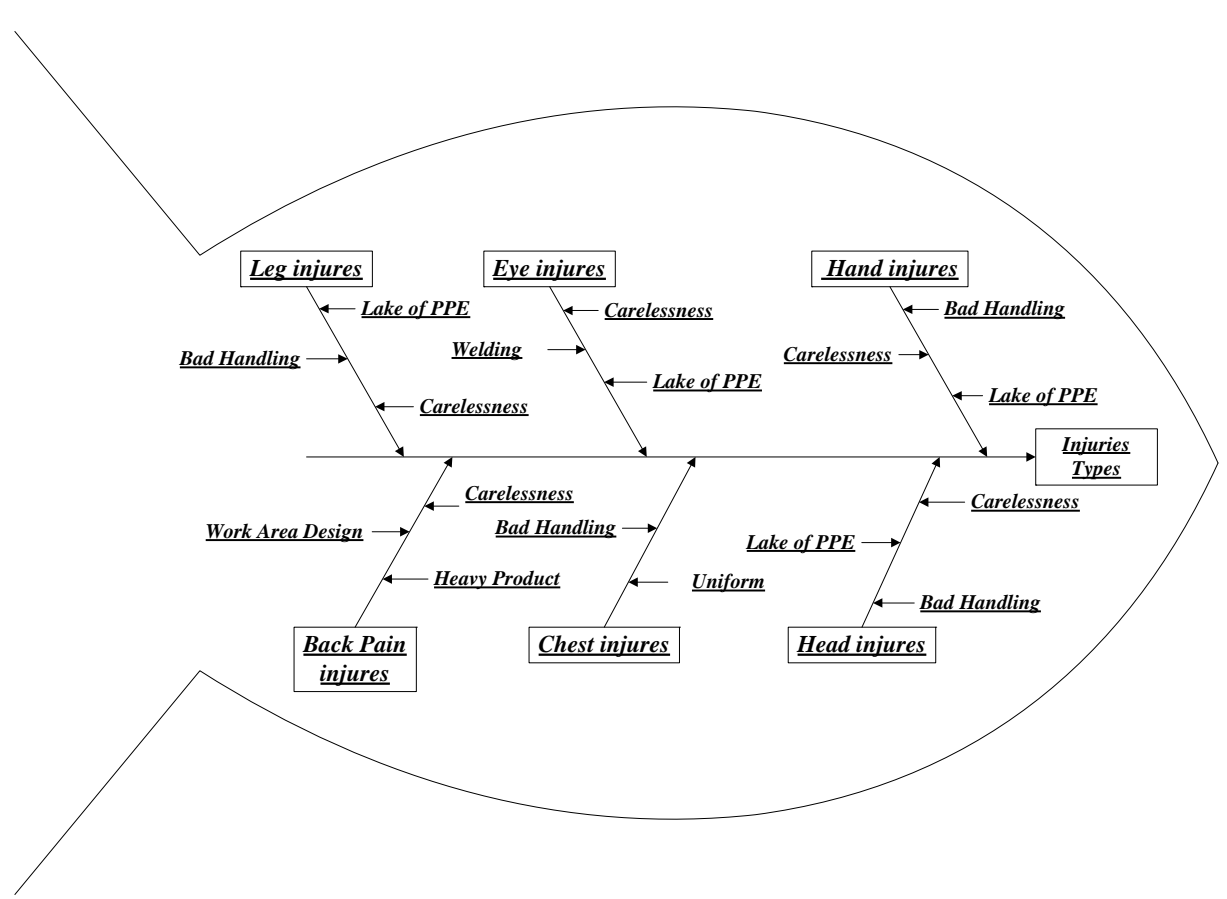

Figure 8. Reasons behind the type of injury.

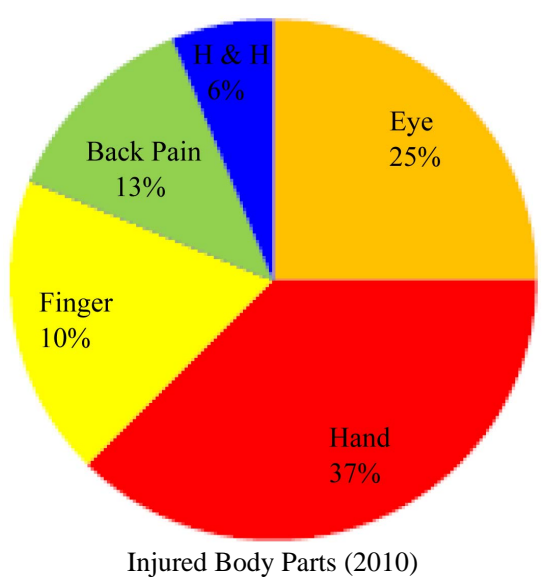

Figure 9. Body part injury rate in finishing department.

\subsection{Improvement and Control Phase}

According to six-sigma technique, once the causes (or critical factors) for safety hazard are identified, one has to suggest the solution to reduce the risk brought by these factors and procedure should be determined. The suggested root causes of these critical factors are documented and went through discussion with the management of the company. The suggested improvements are yet to be implemented, but agreed to implement. The few improvements suggested were as: safety courses should be included in the main induction training program and announce the reward system to anyone who is committed to PPE or other safety regulations. The employee's annual evaluation should have a safety section. Initiate the safety monitoring authority; improve the communication between safety manager and production workers. To document further investigation and give further elaboration on existing situation regarding safety, a visual document was presented with comments. The visual documents were divided into four major categories as: negligence in providing and maintaining the building facilities and utilities, negligence in storage materials and tools, negligence of worker and negligence of management in displaying the safety rules. The sample part of visual docu- 
ment is presented in Figures 10(a) to 10(d).

To have zero injury or to minimize accident rates and or financial loss, control methods are needed. The solutions as presented in the above paragraphs, which includes safety solution, administrative solution, suggestions to improve co-operation among authorities, employers and workers. These control plans are only to sustain the improvements. Specifically, the safety authorities and employers are required to conduct regular inspection. Any problems found should be discussed in daily safety meetings. The authority should inspect the improvement plans on a monthly basis.

\section{Conclusion}

The critical factors related to low safety level at the manufacturing company in Kingdom of Saudi Arabia
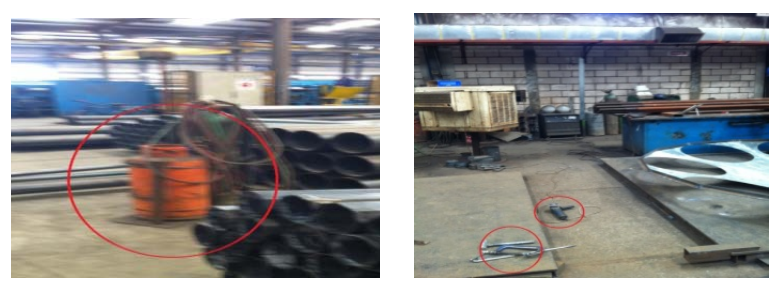

(a)
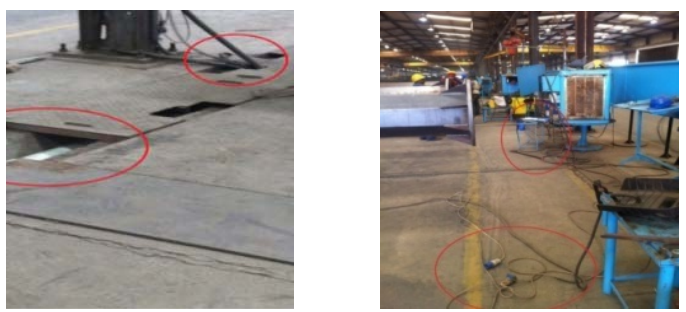

(b)
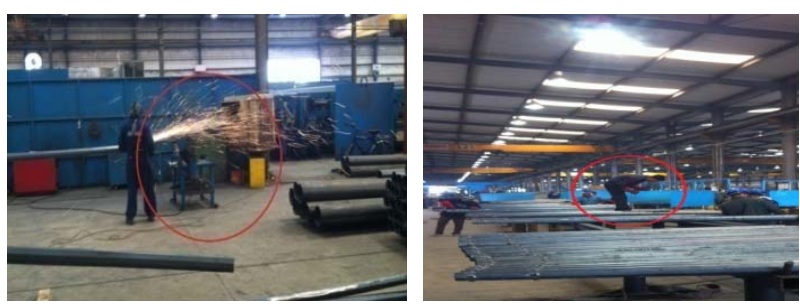

(c)
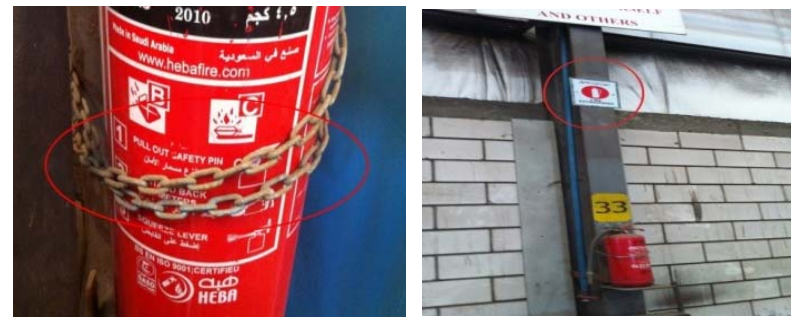

(d)

Figure 10. (a) Negligence in storage materials and tools; (b) Negligence in providing and maintaining the facilities \& utilities; (c) Negligence of worker; (d) Negligence of management in displaying the safety rules. have been identified. From quantitative procedure outlined by six-sigma technique, we identified the critical factors from the questionnaire survey as follows: lack of concentration at work place, disregard to safety regulations, vast variation to co-worker background, and bad handling of tools and materials. From visual observations the factors observed are as: negligence of management in providing and maintaining the facilities \& utilities, negligence of workers in storage materials and tools, negligence of management in displaying the safety rules. Thus the study demonstrates the effectiveness of six-sigma DAMIC approach to reduce the safety hazards. The future scope to the presented study is developing the detail framework for the implementation and control phase.

\section{Acknowledgements}

The authors would like thank the management of the manufacturing company for introducing us to this problem and their help. The authors would also like to thanks the editorial board and reviewers of the journal for accepting the paper. The authors extend their appreciation to the Deanship of Scientific Research at King Saud University for funding the work through the research group project No RGP-VPP-059. Last but not least author also thanks King Saud University for providing a platform to do the research activity.

\section{REFERENCES}

[1] T. Pyzdek, “The Six Sigma Handbook,” McGraw Hill Book Companies Inc, US, 2002.

[2] J. Arthur, "Six Sigma Simplified-Quantum Improvements Made Easy,” Life Star, Colorado, 2002.

[3] A. J. Thomas, H. Rowland, P. Byard and J. Rowland, "Lean Six Sigma: An Integrated Strategy for Manufacturing Sustainability," International Journal of Six Sigma and Competitive Advantage, Vol. 4, No. 4, 2008, pp. 333-354. doi:10.1504/IJSSCA.2008.022948

[4] P. Lok, J. Rodes, A. Diamond and N. Bhatia. "The Six Sigma Approach in Performance Management to Improve Safety Culture at Work," International Journal of Six Sigma and Competitive Advantage, Vol. 4, No. 2, 2008, pp. 151-171. doi:10.1504/IJSSCA.2008.020280

[5] D. Zohar, "Safety Climate in Industrial Organizations: Theoretical and Applied Implications," Journal of Applied Psychology, Vol. 65, 1980, pp. 96-102. doi:10.1037/0021-9010.65.1.96

[6] T. Katz-Navon, E. Naveh and Z. Stern, "Safety Climate in Health Care Organizations: A Multidimensional Approach,” Academy of Management Journal, Vol. 48, No. 6, 2005, pp. 1075-1089. doi:10.5465/AMJ.2005.19573110

[7] A. Zacharatos, J. Barling and R. D. Iverson, "High-Performance Work Systems and Occupational Safety," Journal of Applied Psychology, Vol. 90, No. 1, 2005, pp. 77-93. doi:10.1037/0021-9010.90.1.77 
[8] K. A. Brown, P. G. Willis and G. E. Prussia, "Predicting Safe Employee Behavior in the Steel Industry: Development and Test of a Socio Technical Model,” Journal of Operations Management, Vol. 18, No. 4, 2000, pp. 445-465. doi:10.1016/S0272-6963(00)00033-4

[9] D. A. Hofmann and A. Stetzer, "The Role of Safety Climate and Communication in Accident Interpretation: Implications for Learning from Negative Events,” Academy of Management Journal, Vol. 41, No. 6, 1998, pp. 644657. doi:10.2307/256962

[10] R. Scott Stricoff and J. Seymour Kristen, "Six Sigma Applied to Safety,” ASSE Professional Development Conference and Exposition, Anaheim, California, 10-13 June 2001.

[11] J. Staryarsky and R. Whitfield, "From No Class to 'World
Class' Safety,” ASSE Professional Development Conference and Exposition, Las Vegas, Nevada, 7-10 June 2004.

[12] I. Bahadir and R. Ivan, "Six Sigma Implementation for Ship Maintenance and Safety Management," Annual Conference and Meeting of the International Association of Maritime Economists-IAME, Panama, 12-15 November 2002.

[13] T. Y. Ng, F. Tsung, R. H. Y. So, T. S. Li and K. Y. Lam, "An Application of Six Sigma Approach to Reduce Fall Hazards among Cargo Handlers Working on Top of Cargo Containers," International Journal of Six Sigma and Competitive Advantage, Vol. 1, No. 2, 2005, pp. 188209. doi:10.1504/IJSSCA.2005.006424

[14] M. S. Litwin, "How to Measure Survey Reliability and Validity,” SAGE Publications, London, 1995. 